\title{
The development of a model for predicting the stability boundaries of natural circulation process
}

\author{
V.V. Andreev, E.E. Orekhova, N.P. Tarasova, Yu.S. Perevezentseva \\ vyach.andreev@mail.ru | katrin_orehova@,rambler.ru | tar06@list.ru | khohlova@pochta.ru \\ Nizhny Novgorod State Technical University n.a. R.E. Alekseev, Nizhny Novgorod, Russia
}

\begin{abstract}
The concept of safety for facilities comprising nuclear power plants implies in large the use of passive systems. One of the main passive systems in a nuclear power plant is a system for cooling the reactor core with its action based on gravitational forces. In this regard, the importance of such a physical process as natural circulation is increasing with the development of nuclear power facilities. However, this system has not only advantages but some drawbacks as well. These are the emergence of instability in the two-phase coolant flow, pulsations of thermohydraulic parameters, possible circulation reversal and stagnation. This paper deals with the study of a generalized model of the natural circulation stability. The said model is designed to simplify the design engineering of power equipment. This model will also enable the operating personnel to predict the operating limits of the equipment and remain within the coolant stability bounds. This paper presents a model for predicting the stability boundaries of natural circulation process.
\end{abstract}

Keywords: natural circulation, geyser instability, thermal pulsations, stability

\section{Introduction}

Nuclear energy is currently one of the most promising power sources. The importance of passive safety systems is increasing with the development of the nuclear industry. The main advantage of these systems is the independence of their functioning of external energy sources and as a consequence the simplification of their design. One of the important reactor systems is a passive heat removal system required to cool the core. This system is based on the fluid motion due to difference in specific gravities. The motion occurs without any forcing equipment (no pumps) and represents the coolant circulation generated by the action of natural forces. Moreover, equipment operated with the natural coolant circulation is characterized by reduced installation noise, overall dimensions and the power consumption for self-supply. But notwithstanding these advantages the system has some drawbacks as well, namely, the occurrence of instability in the two-phase coolant flow during the reactor core cooling, pulsations of thermohydraulic parameters and possible circulation reversal and stagnation.

\section{Instability of two-phase flows}

In natural-convection loops with the two-phase coolant condition the flow instabilities are noted, which are manifested themselves through a periodic change in the main thermohydraulic parameters of the flow under constant external conditions. Such unstable flow regime may result in deteriorating reliability of thermal power equipment. Periodic repeated fluctuations in the flow rate of the coolant in the loop may cause the premature loss of the equipment serviceability, the wall material destruction, low-frequency vibrations affecting the operation of the plant as a whole. Furthermore, the loop instability imposes restrictions on permissible limits of the thermal power; therefore, the determination of areas with stable operation of natural circulation loops at low pressures is a very urgent task [1,2].

Destabilizing mechanisms are often associated with design features of a plant using a two-phase flow; the instability may be caused by the availability of a volume equalizer, a hydraulic accumulator or some peculiarities of performances of elements.

\section{Geyser instability}

The results of experimental studies have shown that one of the main types of instability at low pressures and flow rates of the coolant is the flow instability caused by the surge of the coolant boiling in the lifting section of the circulation loop. This type of instability is characterized by periodic emission of a two-phase mixture from the lifting section followed by filling the circulation path with water.

The geysering-type instability was named so because of its resemblance to natural geysers, which are characterized by periodic emissions of a steam-water mixture from the depths of the Earth.

Such geyser instability was first studied in vertical pipes closed from below and filled with water $[3,4]$. When a pipe is heated with some heat flow in the lower part the water boiling begins. In low-pressure systems it results in the sudden increase of steam generation and the rapid discharge of the steam-water mixture into an expansion vessel thereto the pipe is connected. Liquid which is not warmed up to the saturation temperature is discharged from the vessel into the pipe. The system returns to the non-boiling state. The cycle is further repeated $[5,6]$.

The cycle consists of the following several stages:

1) energy accumulation;

2) the coolant boiling at a temperature slightly above the saturation temperature;

3) the emission of a steam-water jet;

4) the return to the initial state.

\section{Methods and techniques for prediction of the coolant flow regimes}

This paper is concerned with the study of the process of natural circulation and its stability using a few different methods in order to create a single generalized system. The following methods have been applied in the work: experimental method, calculation method using computational codes of hydrodynamics, method using artificial neural networks. The results obtained using the said methods are combined to create a generalized model. 
This model shall enable to predict the system behavior, to determine the limiting boundary conditions for the stable operation of the system.

\section{Experimental research methods}

Experimental studies were carried out at the Department of Nuclear Reactors and Power Plants,
Institute of Nuclear Energy and Technical Physics, Nizhny Novgorod State Technical University n.a. R.E. Alekseev.

The experiments were carried out at atmospheric pressure. The system operating modes at atmospheric pressure simulate the emergency cooling process for a nuclear plant.

The scheme of the stand is shown in Fig. 1.

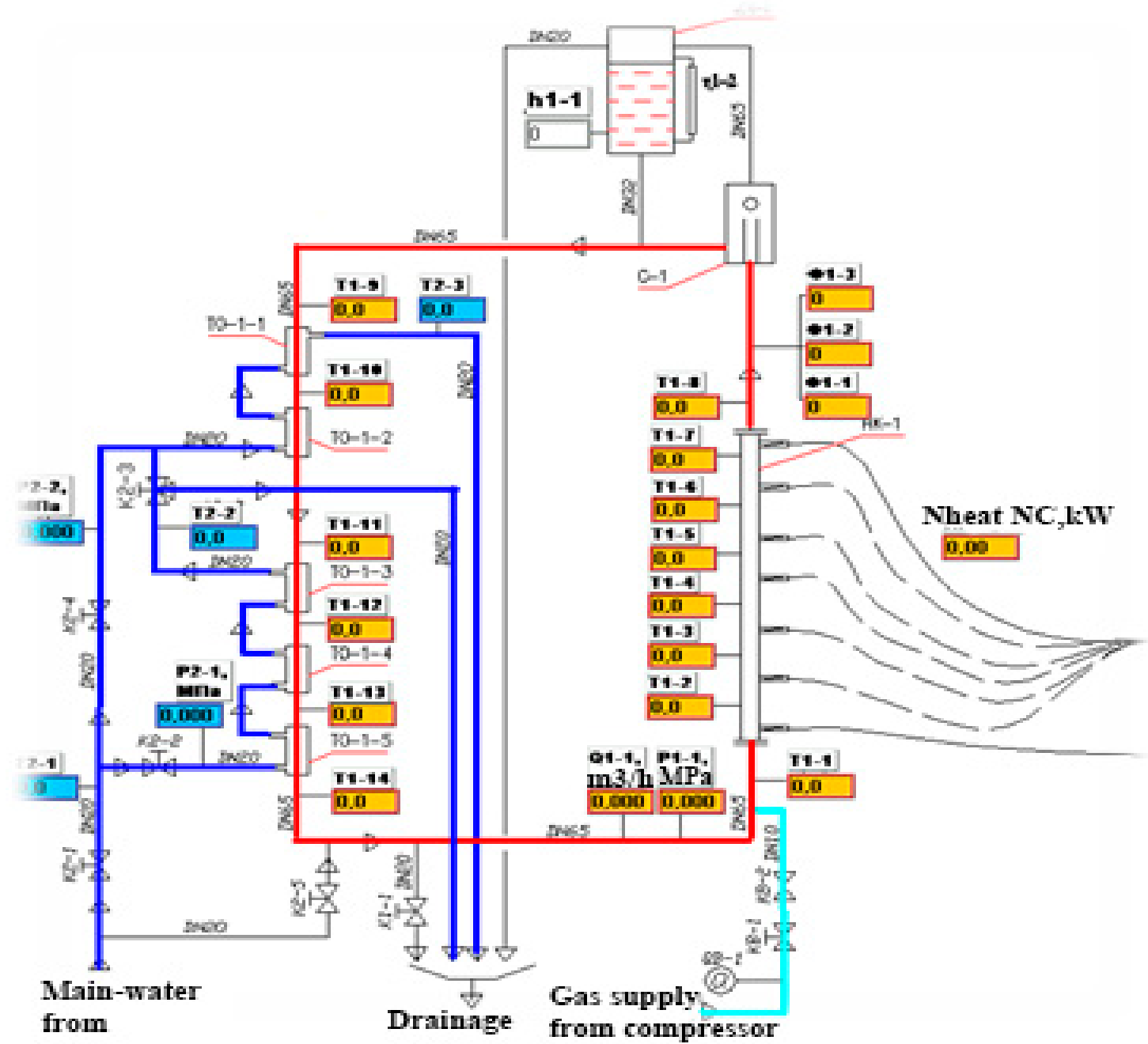

Fig. 1. The scheme of the test stand Designations: TO1-1 - TO1-5 - heat exchangers, T1-2 - T1-8 - thermocouples of the heating section, T1-9 - T1-14 - thermocouples of the cooldown section, T1-1 - T1-3 - thermocouples at the inlet and outlet of the cooling sections, $\Phi 1-1-\Phi 1-3$ - ultrasonic steam sensors

The experiments were conducted as follows:

- measurement of the initial water temperatures in the circulation loop;

- $\quad$ measurement of the initial temperature in the cooling loop;

- measurement of the cooling water flow rate;

- $\quad$ setting of the heater power;

- $\quad$ activation of the data recording and archiving.

Parameters read out:

- $\quad$ heater power;

- refrigerator power;

- coolant temperature at the inlet and outlet of the heating section;

- duct wall temperature along the height of the lifting region:
- cooling water temperature at the outlet of the refrigerator

- differential pressure at the downcomer region

- steam content at the outlet of the heated duct.

Upon setting the pulsation mode the following parameters were recorded: the pulsation frequency and duration, the pressure drop, the coolant temperature at the outlet of the heated section and the pulsation commencement temperature.

\section{Experimental data processing results}

Fig. 2 shows the curve of the natural circulation stability obtained as a result of the experimental data processing. 


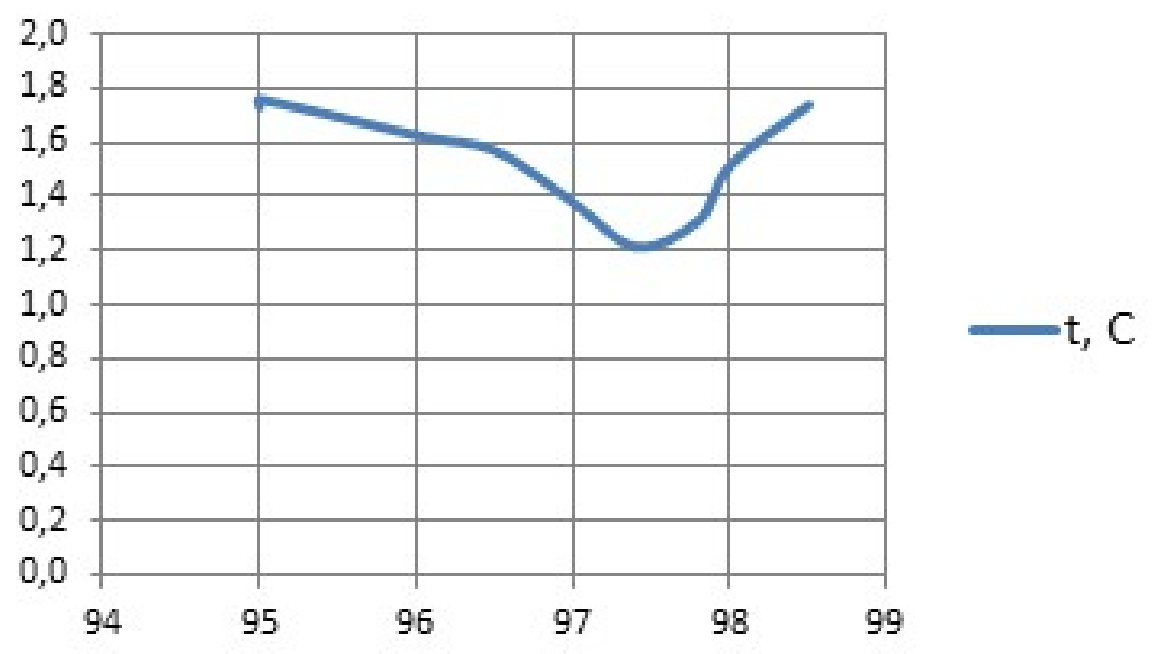

Fig. 2. Experimental Stability Curve

The curve has a left branch bent to the relative temperature axis, a pronounced minimum and a right branch. The operating mode characterized by the right branch includes an interval of the unstable operation of the system. Therefore, the left branch is of particular interest in the results obtained.
Similar results in regard to the natural circulation stability have been found in the literature and are shown in Fig. 3 [7]

Based on the experimental data obtained and found in the literature a technique has been elaborated for creating a generalized model to predict the natural circulation stability.

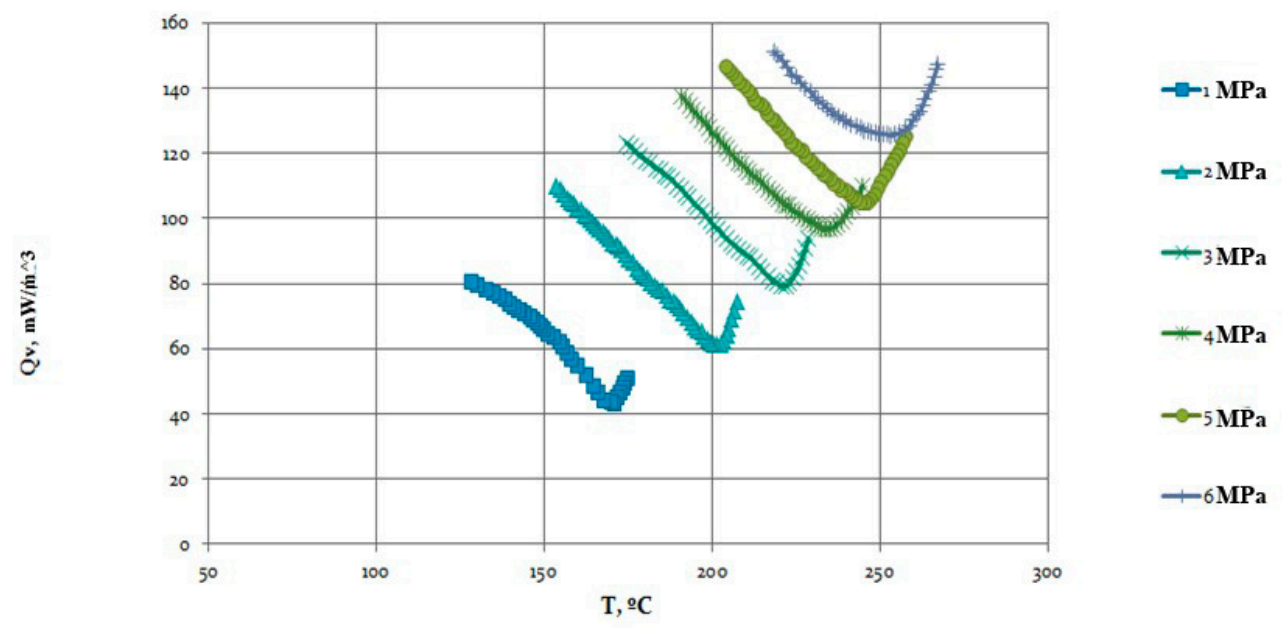

Fig. 3. Stability curves for natural circulation loops

\section{Experimental computational system for studying the natural coolant circulation}

The generalized model is a set of lines showing the boundary conditions for the existence of a stable system constructed on the Q-T axes. Such a combination of boundary conditions is unique for a specific technical system and enables to determine the limits for stable operation of the equipment. The combination of boundary conditions is a family of curves of a characteristic form: the left branch of the family is bent at a certain angle to the temperature axis $(\mathrm{T})$, this angle depends on the geometry of the contour. The salient point (kink) moves depending on the conditions thereunder the coolant is located. The suggested model is shown in Fig. 4
The introduction of generalized coordinates enables us to modify the model under study and reduce it to a simpler form:

$$
\begin{aligned}
& Q_{n p}=\frac{Q v_{0}}{Q v^{*}} \\
& Q v^{*}=f(x=0) \\
& Q v_{0}=f\left(x_{\max }\right) \\
& t_{p}=\frac{t_{0}}{t^{*}} \\
& t^{*}=f(y=0) \\
& t_{0}=x_{\max }
\end{aligned}
$$$$
\operatorname{tg}(\alpha)
$$ 


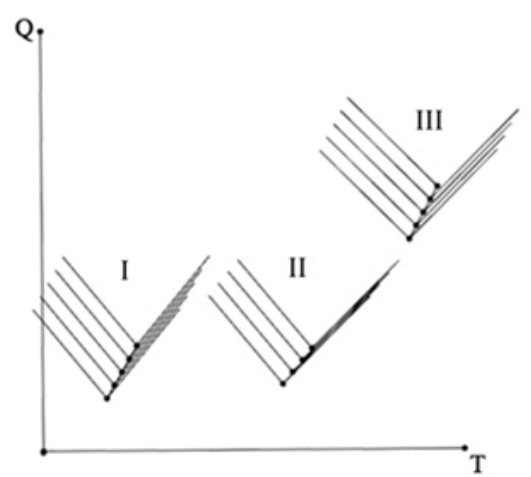

I, II, III - geometrically different circulation loops

a)

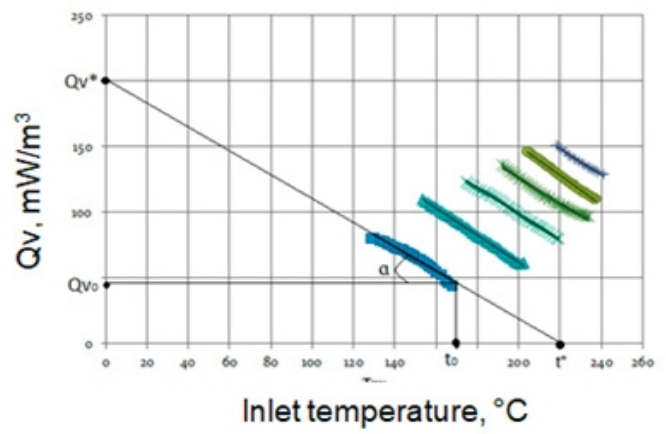

b)

Fig. 4. Peculiarities of boundary conditions for natural circulation in the loop

\section{Generalized model of stability boundaries for systems with natural coolant circulation}

The generalized model is the summary of results obtained using experimental methods, computer simulation and artificial neural networks. This model enables to predict the limiting densities of heat flows therewith the system will still be stable and the coolant boundary temperature at the inlet to the heated section upon exceeding thereof the system will become unstable. This model enables to simplify the procedure of the design and engineering of heat exchange equipment based on the principle of natural circulation. The methodology for constructing such a generalized model is shown in Fig. 5.

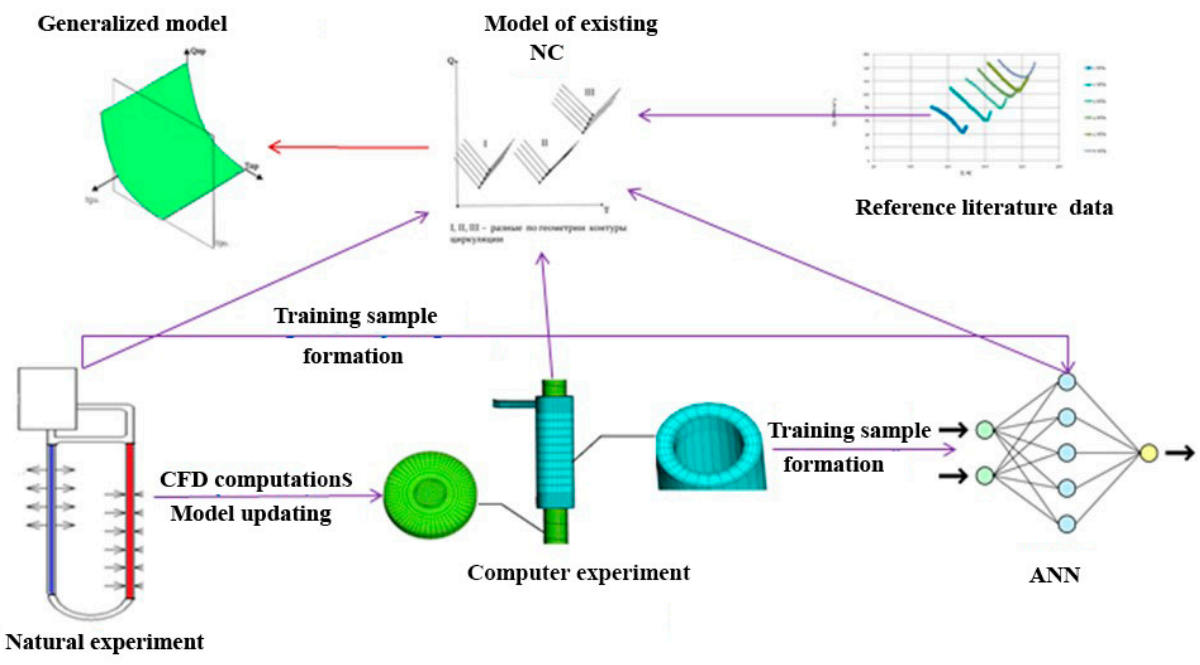

Fig. 5. Scheme of the generalized model

\section{Application of numerical methods for simulation of natural circulation process}

Experimentally obtained results are used to simulate systems using computational fluid dynamics. To apply the computational fluid dynamics method, it is necessary to construct a geometric model of the system under study, to construct a calculation - grid model based on the geometric model, to create a mathematical model.

\section{Methodology for conducting experiments to study the natural coolant circulation by computational simulation methods}

To conduct numerical experiment, it is necessary:

- $\quad$ to create the geometry of the loop under study;

- $\quad$ to create a finite - element model;
- to identify physical and mathematical models of processes studied;

\section{Description of a geometric model used for numerical experiments}

The geometric model is a combination of several components:

- the hot coolant circulation path corresponding to the test stand;

- the coolant circulation path in the refrigerator corresponding to the test stand;

- metal walls of the refrigerator.

All geometrical parameters of the computer model correspond to the natural test-stand under study. The computer geometric model is shown in Fig. 6. 

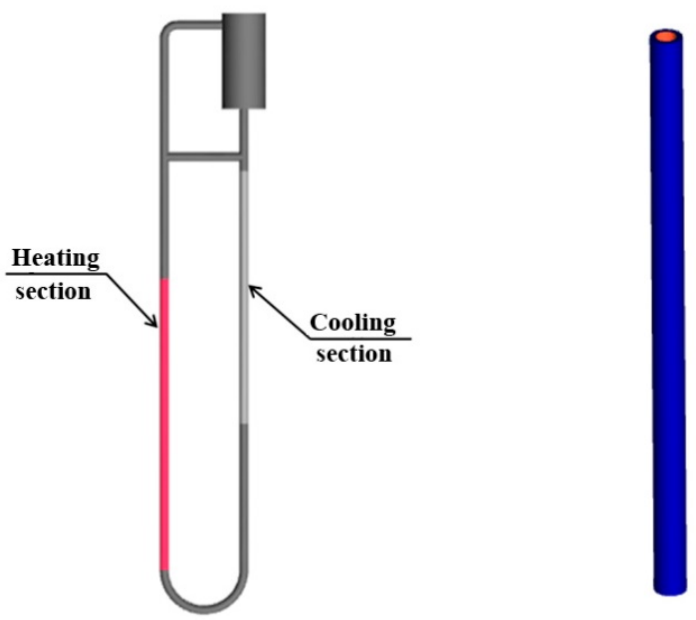

a) circulation loop

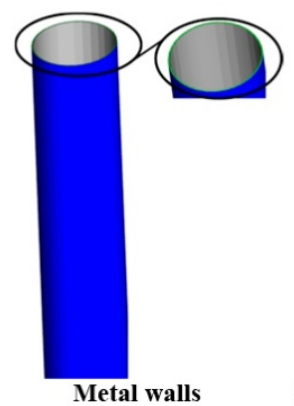

b) coolant circulation loop in refrigerator

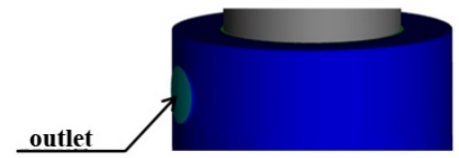

inlet

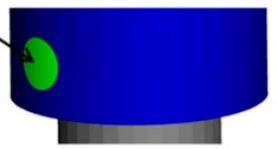

Coolant inlet to refrigerator and outlet therefrom

ter geometric model of the stand

\section{Physical and mathematical model}

The physical parameters of the fluid are simulated as temperature-dependent using an integrated library.

The effect of gravity is taken into account.

The steam generation process is simulated in the system.

The loop walls are simulated without sliding.

The metal heating is set by the specific heat flow on the wall.

The thermal conductivity of metal is simulated.

The refrigerator parameters are simulated by setting the coolant flow rate at the inlet to the heat exchanger;

Description of Mathematical Model

The mathematical fluid model is based on the solution of the system of Navier-Stokes equations [8]:

- the continuity equation:

$$
\frac{\partial \rho}{\partial t}+\frac{\partial\left(\rho u_{i}\right)}{\partial x_{i}}=0
$$

where $\rho$ is the density, ui is the projection of the velocity onto the axis under study, $t$ is time; $x_{i}$ is the coordinate thereon the flow is studied.

- the motion equation:

$$
\frac{\partial\left(u_{i}\right)}{\partial t}+u_{j} \frac{\partial\left(u_{i}\right)}{\partial x_{j}}=-\frac{1}{\rho} \frac{\partial p}{\partial x_{i}}+\frac{1}{\rho} \frac{\partial\left(\sigma_{i j}\right)}{\partial x_{j}}+J_{i},
$$

where indices $i=1,2,3$ shall be the coordinate axis index; $j$ is the summation index; $J_{i}$ is the external force acting on the system (gravity force)

- the energy equation:

$$
\rho \frac{\partial h}{\partial \tau}=-\operatorname{div}(\stackrel{r}{q})+\omega
$$

where $\vec{q}$ shall be projections of the heat flow density onto the coordinate axes; $\omega$ are internal heat sources.

\section{Application of artificial neural networks for simulation of the natural circulation process}

Based on the results obtained using the above methods artificial neural networks (ANNs) are simulated. An ANN of the multilayer perceptron type is used in this work. [9] When simulating ANN, the coolant characteristics of the geometry and state are taken as input parameters. The output parameters are the corrected value of the boundary heat flow and temperature thereat the instability occurs as well as the value of $\operatorname{tg}(a)$ characterizing the position of the curve in space. The ANN simulation scheme is shown in Fig. 7.

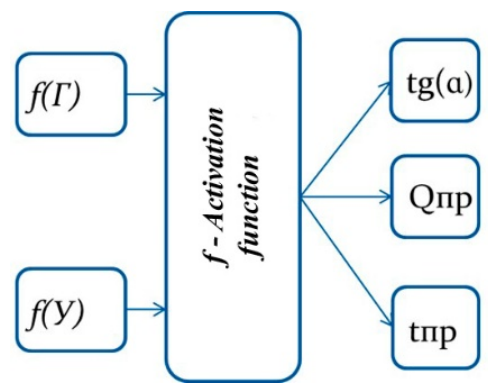

Fig. 7. Scheme of ANN used for generalized model creation $f(\Gamma)$ is characteristic of the circulation duct; $f(y)$ is characteristic of the coolant state conditions; $\operatorname{tg}(\mathrm{a})$, Qпр, tпр are output ANN data - system stability parameters 
When developing a model using artificial neural networks the results of personal experiments have been used as well as the results found in reference data.

It may be noted that in the obtained dependences there is a sharp ascending and descending section. To avoid ambiguity, two neural networks have been simulated: one for each section. However, we lack of knowledge on on the upper limit of each network use because of few experimental data available.
Networks of the multilayer perceptron type with different numbers of neurons in the intermediate layer and several different activation functions have been studied during the simulation.

The analysis of simulated networks is given in Appendix B. Find below the results obtained with a neural network having minimal errors.

\section{$Q^{*}=f\left(t^{*}\right)$}

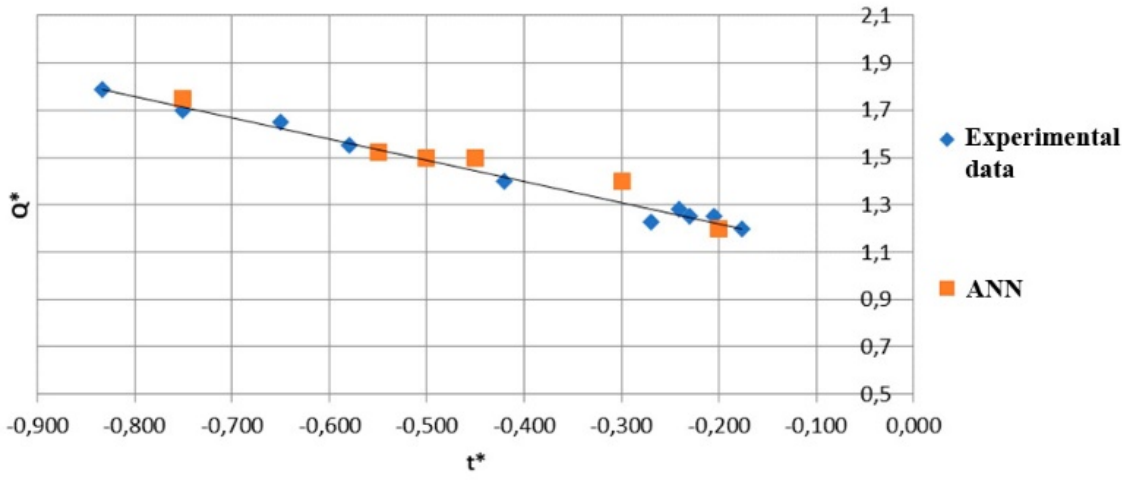

$t^{*}=f(\operatorname{tg}(\alpha))$

$\operatorname{tg}(\alpha)$

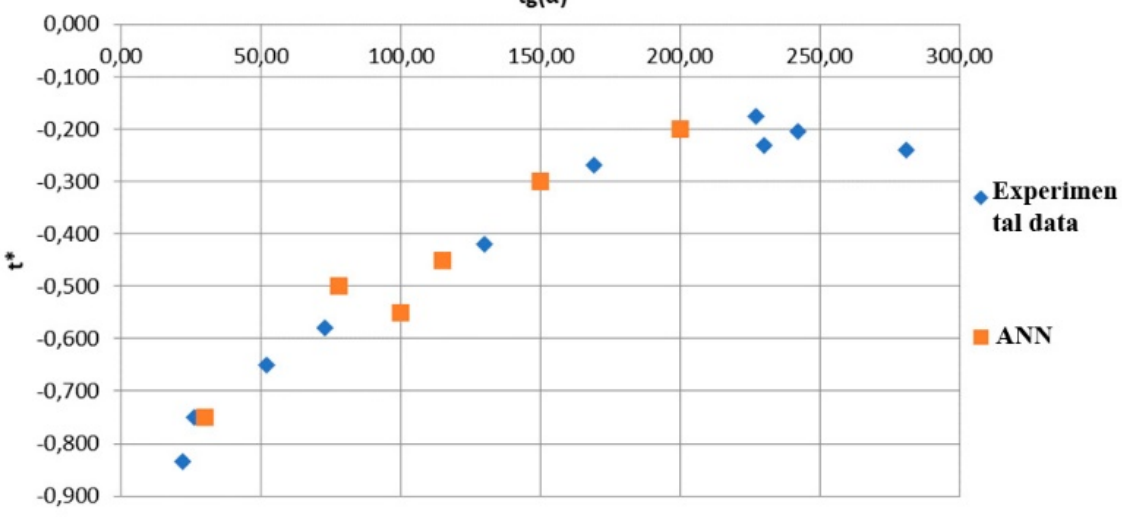

$Q^{*}=f(\operatorname{tg}(\alpha))$

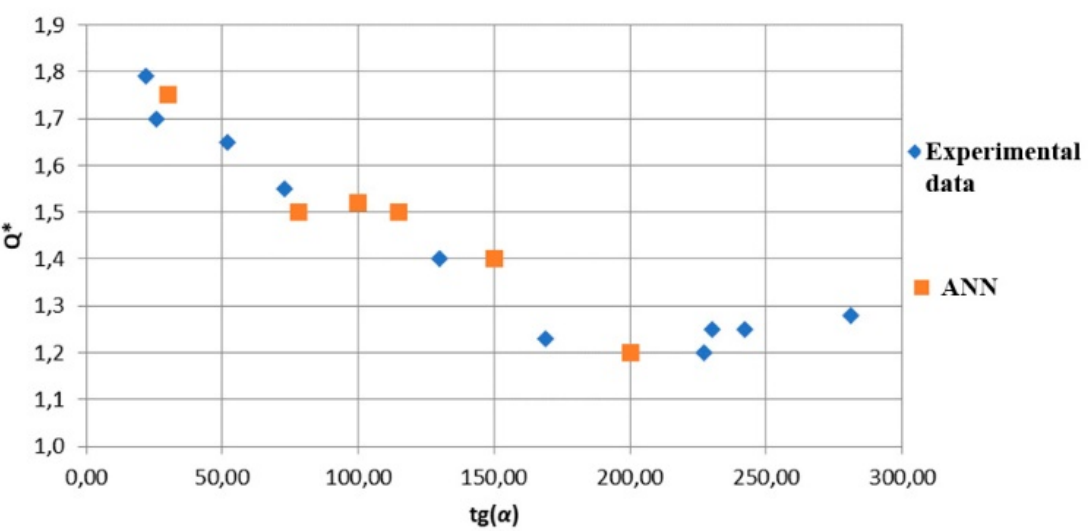

Fig. 8. Results of simulation using ANN

\section{Simulation results}

A set of points has been obtained in the course of the simulation. A boundary stability curve of the natural circulation process corresponds to each point in the spatial coordinate system. It is noted that the said points are on one curve in space and represent an integral system (fig. 9). 


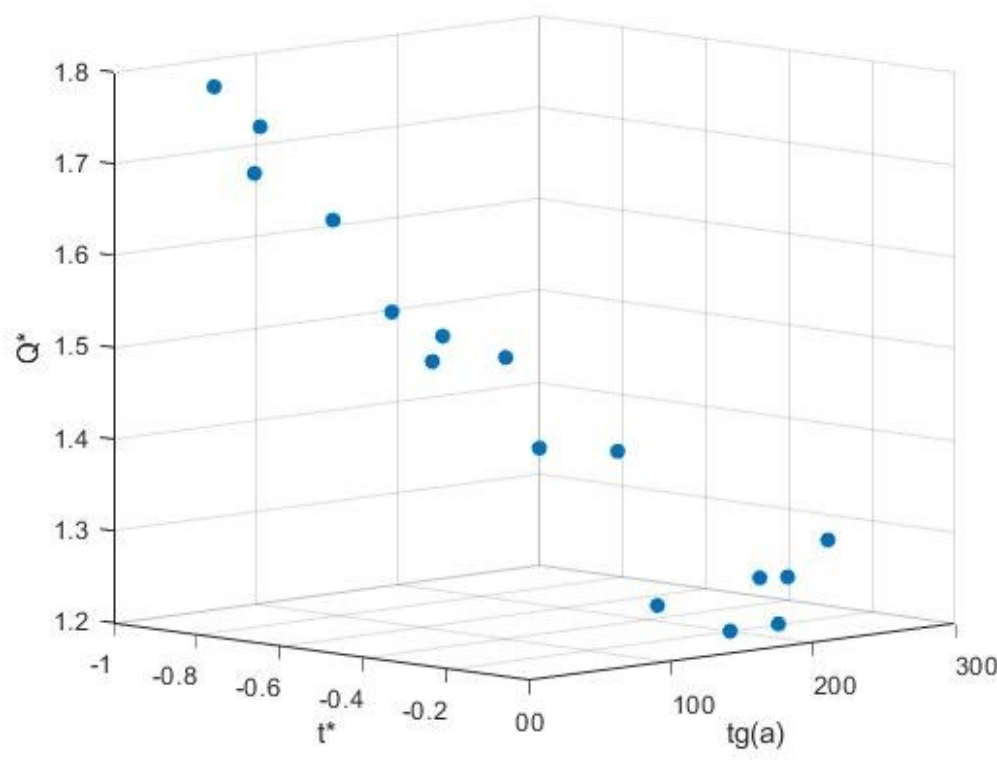

Fig. 9. Type of a generalized curve

\section{Conclusion}

This paper is concerned with the study of the stability boundaries for the natural coolant circulation process. The purpose of the work is to develop a generalized model which enables to predict the stability without reference to a specific geometry, installation or conditions of the system operation. This purpose has been achieved.

The following has been achieved in the course of the work performance:

1. The methodology has been elaborated for conducting full-scale experiments to study the stability limits of geyser instability under the natural coolant circulation using a thermophysical test stand.

2. The methodology has been elaborated for the use of artificial neural networks to predict the stability of the natural circulation process.

3. The generalized model of the natural circulation stability has been developed.

The results obtained may be applied to elaborate technical and organizational measures for process management. This model may also be used to predict the maximum operating conditions of the power equipment with natural coolant circulation.

\section{Acknowledgements}

This work was supported by the RFBR, grant № 1907-00455.

\section{Reference}

[1] Butterworth D., Hewitt G. Heat transfer in a twophase flow // M.: Energy, 1980.

[2] Khabensky V.B., Gerliga V.A. Instability of a heat carrier flow in the elements of power equipment. Saint-Petersburg: Nauka, 1994.

[3] Griffith P. Geysering in Liquid-Filled Lines. // ASME Paper № 62-HT-39, 1962.

[4] Subki M.H., Watanabe N., Aritomi M., Multi Parameters Effect On Thermohydraulic Instability In
Natural Circulation Boiling Water Reactor During Startup // 11th International Conference on Nuclear Engineering. Tokyo. Japan. 2003.

[5] Circulation Boiling Water Reactor During Startup // 11th International Conference on Nuclear Engineering. Tokyo. Japan. 2003.

[6] Takemoto T., Aritomi M., Matsuzaki M., Experimental study on the driving mechanism of geysering // Third International Conference on Multiphase flow. Lyon. France, 1998.

[7] Verbitskiy Yu.G. Modeling of the thermal-hydraulic processes in the elements of the reactor plant equipment at low parameters of the coolant // Sosnovy Bor.: NITI n.a A.P. Alexandrov, 2011. -124 p.

[8] Tong L.S. Heat transfer at boiling and two-phase current. (translated into Russian by Sidorov) // M.: Mir, 1969. - 344 p.

[9] Bykov L.V., Molchanov A.M., Shcherbakov M.A., Yanyshev D.S. Computational mechanics of continuous media in tasks of aviation and space technology. // LENAND, 2015. - 668 p.

[10] Heikin S. Neural Networks: Full course, $2^{\text {nd }}$ edition., translated // «Williams», 2006. - $1104 \mathrm{p}$.

\section{About the authors}

Andreev Vyacheslav V., Head of the Department of Nuclear reactors and power plants, Doctor of Technical Science, Professor, Nizhny Novgorod State Technical University n.a. R.E. Alekseev. E-mail: vyach.andreev@mail.ru.

Orekhova Ekaterina E., Assistant of the Department of Nuclear Reactors and Power Plants, Nizhny Novgorod State Technical University n.a. R.E. Alekseev. E-mail: katrin_orehova@rambler.ru.

Tarasova Natalya P., Senior Lecturer of the Department of Nuclear Reactors and Power Plants, Nizhny Novgorod State Technical University n.a. R.E. Alekseev. E-mail: tar06@list.ru.

Perevezentseva Julia S., Associate Professor of Foreign languages, $\mathrm{PhD}$ in Philology, Nizhny Novgorod State Technical University n.a. R.E. Alekseev. E-mail: khohlova@pochta.ru. 